\title{
Looking Beyond the Toxic Triangle: Connecting Sexual Abuse to Failed Governance in Higher Education
}

\author{
Sara E. Grummert, Ph.D. \\ Institute for Mixed Methods Research \\ Raquel M. Rall, Ph.D. \\ University of California Riverside
}

\begin{abstract}
In this research note, the authors offer an analysis of destructive leadership from an institutional perspective that connects sexual abuse cases to failed governance. By analyzing literature on organizational responses to sexual abuse in intercollegiate athletics, the authors build on the Toxic Triangle of Destructive Leadership and offer a revised framework that places greater emphasis on institutional structures and organizational cultures that enable abusive environments in higher education. In doing so, the authors demonstrate that higher education governing boards are inseparable from the governance structure of the NCAA and call for increased accountability from institutional leadership to proactively prevent sexual abuse.
\end{abstract} abuse

Keywords: destructive leadership, intercollegiate athletics, governing boards, sexual

\section{College Athletics as a Predatory Structure}

There has been heightened attention on how college athletics can function as a predatory structure and subsequently perpetuate harm in raced and gendered ways (Branch, 2011; Cooky, 2012; Gayles et al., 2018; Hawkins, 2013; Hextrum, 2017; Messner, 1988; Sack \& Staurowsky, 1998). In particular, athletic departments and university leadership who enable sexual abuse (used in this paper to encompass sexual assault, harassment, and violence) have become more visible in part due to highly publicized cases of abuse within intercollegiate athletics (e.g., Pennsylvania State University, The Ohio State University, and Michigan State University). Public discourse surrounding recent cases has been more critical of governing board actions. For instance, cases at Pennsylvania State University (PSU) and Michigan State University (MSU) included public calls for governing board members and presidents to be held accountable for how they shielded abusers and/or for their failure to intervene (Seltzer, 2018). In these cases, several board members and presidents have resigned or declined to run for re-election (New, 2016; Seltzer, 2018). However, the public call for accountability from higher education leaders in these high-profile cases does not seem to inspire leaders to examine their organizational structures and culture more broadly, nor implement structural changes to prevent future abuse (Tierney \& Rall, 2018).

Instead, higher education leadership appears to engage in protectionist behavior of various profitable and/or high-profile entities on campus, as is evident in the litany of new and ongoing 
cases (Giroux \& Giroux, 2012). Protectionist behavior is often exacerbated in the context of athletics by governing board members and university presidents who, at the expense of student well-being, shield the entity of intercollegiate athletics from critique (Cooky, 2012; Proffitt \& Corrigan, 2012). Even though research has provided important approaches to address and prevent sexual abuse by changing individual behaviors, attitudes, and investing in bystander intervention (Commitment to an Athlete's Total Success, 2020; Moynihan et al., 2010), there has not been similar urgency toward disrupting the institutional and organizational logics that foster and/or enable sexually abusive environments (Cooky, 2012; Proffitt \& Corrigan, 2012). As we argue, accountability for creating and perpetuating environments ripe for sexual abuse rests not only with individual athletic departments, but also on the overall governance structure and culture of universities (Tierney \& Rall, 2018).

Large scale action and change may be inhibited, in part, due to ambiguity of who is responsible for the governance of intercollegiate athletics. At present, it is unclear who is accountable at the intersection of higher education and sport-institutional governing boards or the National Collegiate Athletic Association (NCAA), the formal governing body of college athletics at member institutions (NCAA, 2017). This jurisdictional ambiguity may be strategically used by institutions to deflect accountability and keep inequitable structures intact (Ahmed, 2012). Through analysis of the NCAA governance structure and the governance structure of higher education at large, we provide a rationale that foregrounds higher education governing boards as the primary governing body of college athletics.

In doing so, we build on the work of Padilla et al. (2007) and offer an analysis of destructive leadership from an institutional perspective, bringing forth a revised framework that implicates university structures and organizational cultures to more accurately evaluate how abusive environments take hold in higher education. To contextualize our call for this conceptual shift, we first elaborate on the function and role of governing boards in higher education and the governance structure of intercollegiate athletics. We then examine the literature related to cases of sexual abuse in athletics and how the abuse is framed (i.e., individually or organizationally). Instead of describing specific cases of abuse, key themes were selected throughout cases that foreground university and governing board actions in the wake of reported sexual abuse.

\section{Governing Boards in Higher Education}

Governing boards of higher education make decisions that permeate all facets of an institution (Rall et al., 2018). An institution's governing board is legally responsible for fiduciary matters, policy, and oversight of a university, making them the owners in a technical sense (Duderstadt, 2004). According to the Association of Governing Boards of Universities and Colleges (AGB), board members have fiduciary duties of care, loyalty, and obedience. Board members are selected primarily through appointments stemming from the state governor, alumni elections, and board member-only elections and appointments (AGB, 2010; Birnbaum, 1988). Because this appointment structure requires no background knowledge of higher education or public policy, and no application process, it is inherently political. In the past decade, an increased focus has been on "public policy and accountability" within higher education governance (Duderstadt, 2004, p. 4). However, many have questioned whether or not governing boards are 
capable of the level of oversight they are tasked with for the university, given that most board members lack any educational or public policy experience (Duderstadt, 2004).

Boards are composed of primarily corporate business executives (Birnbaum, 1988) who are overwhelmingly white men (Campaign for College Opportunity, 2018; Lingenfelter et al., 2008; Westby \& Sack, 1976). The most recent report released by AGB shows that people of color and white women are still vastly underrepresented on higher education governing boards. Their report revealed that $75 \%$ of governing board members and $77 \%$ of presidents at public institutions were white, and $68 \%$ of board members across both public and private institutions were male (AGB, 2016). The lack of board member diversity leads to a potential disconnect between student and institutional needs, especially of those who are minoritized and marginalized by oppressive intuitional structures and values (Rall et al., 2018).

How environmental demands influence institutional practices is not well understood (Pusser et al., 2006), particularly the role of trustees in negotiating these external demands (Nicholson-Crotty \& Meier, 2003; Pusser, 2003; 2006). Governing boards offer a unique example of how broader market forces may influence institutional behavior (Pusser \& Turner, 2004). Governing board members hold considerable power due to their political and professional standing and have the potential to misuse their power to shape policy or curriculum towards an ideology that would benefit their political agenda and/or business interests (Alderfer, 2013; Bastedo, 2009; Duderstadt, 2004; Kaplan, 2006). For example, interviews with 59 university presidents revealed that many were concerned with board members' misuse of power and specifically their loyalty to a political party and/or the governor who appointed them, again highlighting the power that external interests have on board members' decision-making processes (Bastedo, 2009). Board members may be interested in athletics, in particular, for personal and political gain that comes at the expense of ensuring athlete safety and well-being (Bastedo, 2009; Duderstadt, 2003).

Furthermore, tension often exists between the values espoused by faculty and governing boards concerning the goals of college athletics (Smith, 1995). Board members may have their own perception of what athletics means in relation to the university, which can create competing goals between board members and other university stakeholders (Frey, 1987). Governing boards have used athletics as a revenue and prestige-generating promotional tool, while faculty have reported concerns about academic integrity and adherence to the educational mission (Ott \& Bates, 2015; Smith, 1995). In fact, board members may use the institutional governance structure as a mechanism to profit both tangibly and intangibly from big-time athletic departments while remaining relatively anonymous in the shadow of the NCAA (Proffitt \& Corrigan, 2012). A focus on the purview and decision-making practices of governing boards is essential to identify and challenge various injustices rampant in higher education (Rall et al., 2020). We briefly describe the governance structure of the NCAA and athletic departments in the next section to demonstrate that governing boards are inextricably linked to - and thus ultimately accountable - for the governance of college athletics. 


\section{Governance of Intercollegiate Athletics}

The National Collegiate Athletic Association is the formal governing body of intercollegiate athletics in the United States (U.S.; Smith, 2000). The NCAA (formerly named the Intercollegiate Athletic Association) was formed in 1906 by a joint effort from the federal government and institutional leaders in response to an increase of injuries and deaths in college football (Smith, 2000; Westby \& Sack, 1976). The founding of the NCAA as a voluntary member organization initiated more formal rules and regulations for intercollegiate sports. There is a distinction between rule enforcement and rule creation and the NCAA's power is solely to do the former (Yiamouyiannis \& Osborne, 2012). Over time, control and oversight of athletics shifted away from students and faculty and instead toward athletic administrators within the NCAA and individual conference leadership (Westby \& Sack, 1976). Currently, students and faculty have little to no oversight or influence over rule creation or enforcement in college athletics (Smith, 2000).

Critical scholars have documented the fundamentally racist, exclusionary structure of the NCAA - from disproportionate participation and inequitable academic experiences (Comeaux, 2019; Harper et al., 2013; Jayakumar \& Comeaux, 2016), to unequal access and exploitation inherent in the amateur system (Donner, 2005; Gayles et al., 2018; Hextrum, 2020; Sack \& Staurowsky, 1998), to the reinforcement and production of racist ideologies (Gayles et al., 2018; Haslerig et al., 2020; Hawkins, 2013; Hextrum, 2019). These dynamics are also reflected in who holds powerful leadership positions within the NCAA. The NCAA is currently comprised of 1,117 member institutions, with each institution having one individual, usually the university president, serving as the institution's representative (NCAA, 2017). The overrepresentation of white men holding board member positions spills over into NCAA member institutional representation; white male governors overwhelming appoint white male governing board members, which in turn appoint white male university presidents, who then appoint white men to pivotal administrator roles on campus including, but not limited to, the athletic director post (Rall et al., 2018; Rall \& Orué, 2020). Consequently, this cyclical process excludes people of color and white women from NCAA senior leadership (Yiamouyiannis \& Osborne, 2012).

The most influential and highest-ranking governing body of the NCAA is the Board of Governors, formerly known as the Executive Committee (NCAA, 2017). The Board of Governors has 16 voting members from various divisional classifications and each representative is a university president. As such, NCAA leadership is inseparable from university leadership and institutional values are reflected in what the NCAA chooses to enforce and vice versa. Due to the control governing boards possess over presidential leadership — and subsequently, NCAA leadership_-governing boards are inherently accountable for college athletics.

\section{Athletic Departments}

Internally, athletic departments have a hierarchical structure that concentrates administrative power and oversight in the position of the athletic director (Ott \& Bates, 2015). However, symbolic and institutional power is often obscured or ambiguous within departments. For example, problematic concentrations of power may form as an individual accumulates more power, (e.g., a head football coach or athletic director) leading to fewer checks and balances over 
time (Luther, 2016). This may be, in part, due to closed systems within athletic departments and no formal, uniform campus apparatus to provide oversight (Frey, 1987; Ott \& Bates, 2015). Individual athletic departments often have their own structure of reporting that can be vastly different from academic departments on campus and many athletic directors report directly to their university president or governing board (Brand, 2006). With regard to reporting sexual abuse specifically, a 2014 U.S. senate report revealed that more than $20 \%$ of surveyed public and private institutions allow athletic departments to investigate sexual assault reports on their own (U.S. Senate, 2014). In other words, sexual assault investigations are solely within the purview of individual athletic departments and there is no oversight of investigations.

In addition to these large structural flaws that isolate athletic departments from the broader university community, it has been found that many athletic department cultures silence victims of sexual abuse and discourage reporting (Gutierrez \& McLaren; 2012; Luther, 2016). Examples of silencing tactics include university officials suggesting mediation in lieu of a formal investigation, suggesting that accusers drop charges, shielding accused administrators and staff from police, and broadly enacting and encouraging a culture of silence (Gutierrez \& McLaren, 2012; Luther, 2016). As we discuss in depth below, cultures of silence reinforce the centering of athletics as an entity that is cyclically protected by institutional power and accumulates more power at the expense of students and ethical decision-making (Cooky, 2012; Sartore-Baldwin et al., 2017).

\section{Conceptual Framework}

To prevent and appropriately address sexual abuse in college sport, it is important to focus on the organizational context that allows and enables abuse to occur. The Toxic Triangle of Destructive Leadership helps analyze organizational actors within higher education institutions, such as governing boards and athletic administrators, as it provides an analysis of individual actions, leadership characteristics, and contextual factors that contribute to a destructive leader's power and influence. Stemming from the study of psychology, social psychology, and organizational leadership, the Toxic Triangle of Destructive Leadership was developed to illustrate the convergence of a destructive leader, susceptible followers, and an unstable environment that enables abuse (termed a conducive environment; Padilla, 2012; Padilla et al., 2007). The destructive leader often weaponizes their charisma and power within the institution to further their personal goals (Padilla et al., 2007). Susceptible followers are divided into subgroups of colluders or conformers in which colluders often possess the same deleterious values as the destructive leader, and conformers may have low self-efficacy and/or an external locus of control. Lastly, a conducive environment can be constructed through organizational instability, outside threats, and/or the lack of adequate checks and balances (Padilla et al., 2007).

Prior scholarship has applied the Toxic Triangle of Destructive Leadership and other organizational frameworks to analyze how sexual abuse has been perpetuated within athletic departments (Alderfer, 2013; Thoroughgood \& Padilla, 2013). We briefly review and extend this literature to construct a larger, institutional perspective of destructive leadership as it pertains to higher education. As we demonstrate, an over-emphasis on individual perpetrators within athletic departments may inhibit a larger institutional analysis of how abuse is enabled in higher education and complicated by the governance structure of intercollegiate athletics. Due to the paucity of literature researching the role of governance in sexual abuse cases within college athletics, peer- 
reviewed journal articles and scholarly books were paired with essays, as well as investigative reports in our analysis.

\section{Destructive Leadership in Intercollegiate Athletics}

Scholars and journalists have documented and analyzed cases of sexual abuse occurring in college athletics for decades, often focusing on the perpetrator or the athletic department itself (Belson, 2012; Freeh et al., 2012). This individualistic focus, whether on leader or perpetrator, likely inhibits large-scale organizational and societal change. In recent years, there has been a shift in the discourse that has seemingly broadened the scope of blame and analysis to larger groups and/or organizations. In the oft-cited case of Penn State, several scholars have analyzed the sexual abuse committed by former football assistant coach Jerry Sandusky using a less leader-centric focus. Alderfer (2013) analyzed the case of abuse at Penn State from a group and intergroup perspective, whereby he analyzed several university groups (e.g., coaching staff, senior-level administrators, and the board of trustees), community groups (e.g., police, Second Mile foundation, families of the victimized), and the mechanisms for how their respective group dynamics enabled abuse. For example, the lack of unity and various subgroups that formed within the board of trustees funneled power to president Spanier, who subsequently shielded coach Joe Paterno, Sandusky, and the athletic department from culpability (Alderfer, 2013).

Thoroughgood and Padilla (2013) found similar dynamics at PSU. Using the Toxic Triangle of Destructive Leadership, they outlined various stakeholders within the university that contributed to the abuse. They described the conducive environment as a combination of weak faculty oversight, biased board members with a vested interest in athletic success, and an absence of checks and balances over prominent leadership personnel (e.g., former football coach Paterno and president Spanier). Susceptible followers who indirectly contributed to the abuse included the athletic director, president Spanier, coach Paterno, and the Board of Trustees (Thoroughgood \& Padilla, 2013). Investigative journalists have documented similar themes in other recent cases of organization-wide sexual abuse that took place within Baylor University, The Ohio State University, and MSU athletics (Brown, 2018; Freeman, 2018; Solomon \& Luther, 2015; Trombino \& Funk, 2019). In each of these cases, much of the focus has been on coaches, athletic staff, presidents, and members of the board that are framed as susceptible followers who indirectly contributed to the conducive environment.

It is important to note that the toxic organizational behavior described here is not exclusive to institutions with high-profile athletics programs. Even institutions with less notable athletic departments enable abuse and engage in similar tactics to shield themselves from accountability. For example, multiple cohorts of women's college basketball players at the University of California Riverside (UCR) reported decades of abusive and hostile conditions created by their former head coach Margaritis (Fernandez, 2019). After reports gained local traction, students and the surrounding community called for his termination and the administration placed him on leave - he was later fired. However, the assistant coach who stood in solidarity with players and attempted to disrupt the abuse was informed that her contract would not be renewed for future seasons (Fernandez, 2019). The seemingly retaliatory action of university leadership likely reinforced a culture of silence and suppression, similar to that which is rampant across larger athletic programs (Gutierrez \& McLaren, 2012). 
Importantly, governing boards and presidents in all aforementioned cases were negligent in their oversight function, had a lack of transparency during and after investigations, and deflected accountability for the role they played in enabling the abuse. Governing boards were able to operationalize the governance structure, namely the function to delegate and power to terminate, to shield themselves from responsibility. At both Baylor and MSU, governing boards deflected blame onto the president of the institution and coaches. Even though the removal of the presidents and coaches was warranted, governing board members were not properly investigated nor held accountable for the ramifications of their lack of oversight. Locating harm exclusively within individuals (i.e., a president or coach) and subsequently removing those individuals reinforces a culture that seems to equate preventing sexual abuse with preventing an individual violation-a logic that prevents structural change; instead, this often creates a "culture of compliance" or "culture of silence," whereby the organization discourages reporting abuse to avoid violations, rather than meaningfully addressing harm and violence (Doyle, 2015; Giroux \& Giroux, 2012, p. 268; Grossman, 2003, p. 3).

More recently, interim presidents and university leadership at many of the aforementioned institutions have perpetuated the same problematic culture. For example, Baylor's director of student activities reportedly attended victim-support groups and allegedly shared information with other administrators to shape their message (Bauer-Wolf, 2018). At MSU, the interim president questioned victims' intent in suing the university and insinuated that they were profiting from Nassar's criminal trial (Seltzer, 2018). Disturbingly, the formal governing body of collegiate athletics (the NCAA) concluded that there was no wrongdoing on behalf of MSU in their handling of Nassar's abuse (Roth, 2018). Their conclusion draws attention to the absence of legislation that protects the well-being of college athletes who are the students the NCAA claims to serve (NCAA, 2018a). Perhaps less intuitively, the NCAA's response to sexual abuse reflects member institutions' values and the NCAA's limitations - there is an absence of formal avenues for athletes and staff to report abuse, no mandated sexual abuse reporting procedures, and general apathy toward addressing how the structure of athletics within higher education enables abuse to occur (Cooky, 2012; Luther, 2016).

Given the absence of enforceable legislation from the NCAA, governing boards function, by default, as the sport governing body for their respective institutions. Centering this reality is important to implicate governing boards when abuse occurs in athletics. Governing board actions in the aforementioned cases prioritized athletics and the symbolic currency and prestige athletics garners over the well-being of students (Alderfer, 2013; Cooky, 2012; Giroux \& Giroux, 2012). Importantly, the perception of value or prestige of athletics is both real and imagined. As evidenced by the case at UCR, institutions seem inclined to adopt similar protectionist strategies whether or not they house a big-time athletic program. Protectionist behavior is not just a matter of prioritizing athletics above all else, but a symptom of failed shared governance in which leaders act in ways that harm all aspects of the institution (Giroux \& Giroux, 2012). Over the last decade, scholarly literature and investigative reports have provided a more nuanced approach to destructive leadership. A framework that foregrounds institutional structures and organizational cultures of universities is needed to provide a better conceptualization of how abuse persists within organizations in order to enact structural change. 


\section{Reconceptualizing Destructive Leadership}

The development of conceptual models to better elucidate topics related to college athletes have been useful in the realm of college athletics (Comeaux \& Harrison, 2011). Padilla et al.'s (2007) original model of destructive leadership may limit analysis of how institutions foster abuse on a broader level and instead keep the focus on athletic departments, athletic culture, and specific destructive individuals within departments. Governing board members and other influential leaders are often shielded from critique, thus preventing large-scale change. It would be beneficial for higher education and athletic administrators to reconceptualize sexual abuse as an institutional failing, rather than place blame solely on an abusive individual who was enabled by their most direct sphere of influence. As stated by Tierney and Rall (2018), "Without an analysis of the larger environment in which these organizations function, the onus falls on individual action rather than systemic change" (p. 12). Reconceptualizing destructive leadership as a broader institutional and organizational phenomenon leads to an analysis of other powerful entities within institutions, e.g., governing boards, as well as the external forces and societal pressures that influence decisionmaking.

Reconceptualizing destructive leadership from an institutional perspective calls for the conducive environment to be emphasized as the central force that enables toxic cultures and abusive behavior (see Figure 1). An institutional approach to destructive leadership places the focus on the institution and its sociohistorical context as a conducive environment. The conducive environment is not simply an accomplice to a destructive leader. Rather, the conducive environment is the all-encompassing force in which abuse is fostered. Evaluating a conducive environment for abuse in sport requires an analysis of external forces and pressures, institutional structures, organizational culture, and subcultures on campus. 


\section{Figure 1}

Evaluating Conducive Environments for Abuse in Sport

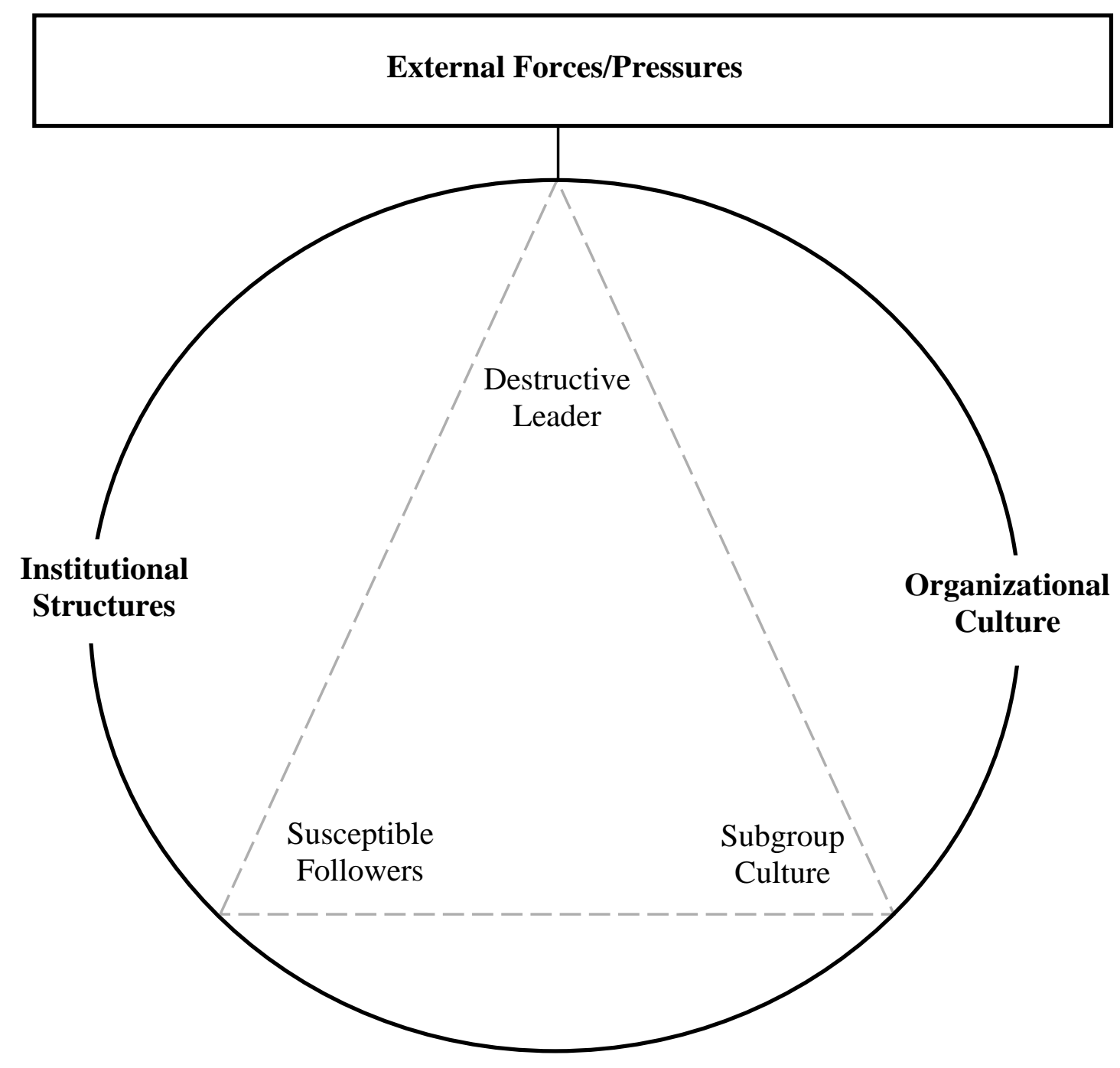

Note. Adapted from The Toxic Triangle of Destructive Leadership by Padilla et al., 2007.

Institutional structures and organizational culture are central to this framework. As in Padilla et al.'s (2007) original framework, the destructive leader and susceptible followers remain. However, external pressures have been included to contextualize outside forces (i.e., systems of oppression, market or economic pressures, political or community influence) that shape institutional structures, organizational culture, and institutional responses to abuse. Structurally, higher education institutions may foster and contribute to abuses of power (in this case sexual abuse) through oppressive leadership mechanisms. These may include appointment processes for governing board members that perpetuates white male leadership with limited higher education experience, no accountability mechanisms for governing board members, and/or problematic or nonexistent reporting procedures for racial and gender violence. Though organizational culture 
can often be difficult to define, many scholars agree that organizational culture consists of shared values, beliefs, and assumptions (Barney, 1986; Tierney, 1988). Organizational culture is reflected in "decisions, actions, and communication" both literally and symbolically (Tierney, 1988, p. 3). Subgroup culture has also been included to highlight how various subgroups within an institution may have different or conflicting values within the larger institution (Bolton \& Kammery, 1972; Jayakumar \& Museus, 2012).

Importantly, conflict between subcultures and/or the institution should not be viewed as detrimental to the organization (Tierney \& Rall, 2018). In fact, agreeability between groups should be a cause for concern, as it may be a symptom that a toxic organizational culture exists. "Dynamic tension" between subcultures in an organization may help combat abuse both on the individual and institutional level by bringing attention to conflicting interests and encouraging dissent (Tierney \& Rall, 2018, p. 12). Rather than viewing and treating sexual abuse in college sport as a localized problem, scholars, practitioners, and campus leaders must connect abuse to governance structures and reflect on the ways their organizations enable abuse to occur through oppressive organizational cultures and institutional policies. The revised framework we put forth is intended to serve as a tool to broaden the conceptual analysis of sexual abuse in college sport and highlight how governance structures are directly implicated in enabling abuse in higher education.

As exemplified in the cases we reviewed, institutions often mask sexual abuse by instilling a culture of fear and retaliation, rather than encourage reporting and feedback. Disrupting a culture of retaliation and insularity, which so often deters people from reporting abuse, may be the first step toward being proactive in preventing abuse and holding leadership accountable. For athletic departments, in particular, leaders should ask themselves and their organization: Is there a mechanism in place for athletes and staff to report abuse and feel safe and supported doing so? How does the structure of governance within the university either reinforce or disrupt the siloing of athletic departments on campus? In what ways can the university community hold leadership accountable through shared governance (i.e., oversight from the academic senate, survivors, student committees, etc.)?

Further, our analysis demonstrates the need for higher education to determine (and consistently adhere to) which governing body is responsible and accountable for preventing abuses of power within athletics. While institutional leaders and stakeholders have gathered to fill this oversight role when the issue is academic integrity (American Council on Education, 2016), no clear entity has assumed this sort of role for issues related to the safety and well-being of college athletes. Based on institutional bylaws that often tout the breadth and reach of the control and authority of governing boards, this decision-making body should be considered as the entity ultimately responsible for the governance of college athletics. This does not preclude governing boards from delegating the role to another decision-making body like the NCAA, but it does necessitate that governing boards assert their authority in this space. This authority needs to be clearly delineated in higher education because ambiguity only allows abusive environments to fester. The assumption of this power by governing boards is a necessary but insufficient step for higher education institutions to reign in on sexually abusive acts and environments. Cultural change cannot be unilaterally left to boards and it certainly does not stop with them. Fundamental governance processes (i.e., appointment procedures, board member background and experience, member values, etc.) must also change (Rall et al., 2018; Rall \& Orué, 2020), which means the 
involvement of other influential stakeholders. Higher education and athletic department administrators must shift institutional oversight structures toward shared responsibility (e.g., academic senate and student committees, third-party advocacy groups) and value transparency for any substantive change to occur (Parent \& Demers, 2011; Sartore-Baldwin et al., 2017).

Last, without an understanding of intersectionality and a commitment to challenging oppressive ideologies, transformative change is unlikely to occur (Harris \& Linder, 2017). Sexual abuse is enabled by overlapping and co-constitutive systems of white supremacy, patriarchy, heterosexism, ableism, and other forms of oppression (Crenshaw, 1991; Harris \& Linder, 2017; Linder \& Harris, 2017; Williams, 2017). Scholars and practitioners should look toward the work of INCITE Women of Color Against Violence Collection (2016) and the research of Jessica Harris and Chris Linder, among others, for developing "power-conscious frameworks" that are informed by an intersectional analysis and detail specific action to address and eradicate sexual violence on college campuses (Linder, 2018, p. 110).

\section{Conclusion}

AGB has concluded that some of the most profound failures of higher education governance recently have come from inadequate attention to intercollegiate athletics (AGB 2014a). Concerns about negative publicity and ongoing public debates about the business model of college sport and athlete rights seem to further disincentivize transparency about organizational failings, even though such transparency would lead to healthier environments for all stakeholders (NCAA, 2018b). The present analysis highlights a systemic structural and cultural failure within intercollegiate athletics and higher education governance. Presidents and trustees, regardless of intent, continue to make decisions that reproduce harm and prioritize the entity of athletics over student well-being (Cooky, 2012; Nixon, 2014). Connecting cases of sexual abuse to failed governance can help institutions assess where power is concentrated and perhaps weaponized within the institution, locate structural interventions to increase accountability and transparency, and ultimately re-prioritize athlete safety and well-being (AGB, 2014b).

This research note also reminds scholars, policymakers, and leaders in higher education that the potential for ethical misconduct pervades colleges and universities more than we assume, and even more than we feel comfortable acknowledging. The pull of ethical fading is powerful (Tenbrunsel \& Messick, 2004). Institutional leadership and stakeholders must confront the pull of ethical fading and the devastating effect it can have on enabling sexual abuse. Simply put, avoiding discussions about sexual abuse does not prevent future abuse - a statement that is self-evident but often counter to the logic of stakeholders at the nexus of athletics and higher education (Cooky, 2012; Parent \& Demers, 2011). The negative implications of a strong, agreeable organizational culture may present moral hazards that scholars in higher education have yet to explore in detail, especially in athletics. The same deep emotional engagement to athletics that bestows a unique sense of belonging and pride to members of a university may distort the decision-making frames of university administrators, allowing them to prioritize their sense of the institution's best interests over ethical decision-making.

To be clear, we are not arguing that individuals should be exempt from personal responsibility for sexual abuse and/or ethical misconduct. When trustees, administrators, faculty, 
staff, and students violate ethical standards such as failing to report a sexual predator and protect children from sexual abuse, they must be held accountable. However, if our scholarly community is serious about informing the design of more ethical institutions, we need to acknowledge that misconduct is an institutional problem that demands structural solutions in addition to individual consequences. Though we examine higher education governance, the model and concepts presented are generalizable to other sporting contexts and forms of abuse. At the core, enabling sexual abuse is an issue of power that is weaponized in various organizations and contexts (Linder, 2018).

The conceptual framework discussed in this text will help higher education administrators and athletic personnel better prevent and identify abuse in their organizations. Scholars have lamented the limited theoretical models designed to improve our understanding and knowledge of college athletes within the higher education setting (Comeaux \& Harrison, 2011); the revised framework for evaluating conducive environments for abuse in sport provides higher education leaders with a tool for conceptualizing and evaluating how their organization may be fostering abusive conditions that so often pervade athletics. By understanding these structural, organizational, and environmental factors, postsecondary leaders can begin to address the full scope of ethical misconduct pertaining to athletics across our nation's campuses. 


\section{References}

Ahmed, S. (2012). On being included: Racism and diversity in institutional life. Duke University Press.

Alderfer, C. P. (2013). Not just football: An intergroup perspective on the Sandusky scandal at Penn State. Industrial and Organizational Psychology, 6(2), 117-133.

American Council on Education. (2016). The student-athlete, academic integrity, and intercollegiate athletics. https://www.acenet.edu/Documents/ACE-Academic-IntegrityAthletics.pdf

Association of Governing Boards of Universities and Colleges (2010). Policies, practices, and composition of higher education coordinating boards and commissions. Washington, DC: Association of Governing Boards of Universities and Colleges. https://agb.org/sites/default/files/legacy/2010CompositionSurvey_Report.pdf

Association of Governing Boards of Universities and Colleges. (2014a). Consequential boards: Adding value where it matters most. https://agb.org/trusteeship-article/consequentialboards-adding-value-where-it-matters-most/

Association of Governing Boards of Universities and Colleges. (2014b). A wake-up call: Enterprise risk management at colleges and universities today. http://agb.org/sites/default/files/legacy/RiskSurvey2014.pdf.

Association of Governing Boards of Universities and Colleges. (2016). Board demographics. https://www.agb.org/blog/2016/05/12/board-demographics-infographic

Barney, J. (1986). Organizational culture: Can it be a source of sustained competitive advantage? The Academy of Management Review, 11(3), 656-665.

Bastedo, M. N. (2009). Conflicts, commitments, and cliques in the university: Moral seduction as a threat to trustee independence. American Educational Research Journal, 46(2), 354386. 
Bauer-Wolf, J. (2018, August 27). A mole at Baylor? Inside Higher Ed. https://www.insidehighered.com/news/2018/08/27/baylor-accused-planting-mole-sexualassault-advocacy-groups

Belson, K. (2012, July 13). Abuse inquiry faults Paterno and others at Penn State. The New York Times. https://www.nytimes.com/2012/07/13/sports/ncaafootball/13pennstate.html

Birnbaum, R. (1988). How colleges work: The cybernetics of academic organization and leadership. Jossey-Bass.

Bolton, C. D., \& Kammeyer, K. C. (1972). Campus cultures, role orientations, and social types. College and Student: Selected Readings in the Social Psychology of Higher Education, 377-391.

Branch, T. (2011). The shame of college sports. The Atlantic. https://www.theatlantic.com/magazine/archive/2011/10/the-shame-of-collegesports/308643/

Brand, M. (2006). The role and value of intercollegiate athletics in universities. Journal of the Philosophy of Sport, 33(1), 9-20.

Brown, S. (2018, July 6). Larry Nassar's former boss is out at Michigan State. The Chronicle. https://www.chronicle.com/article/Larry-Nassar-s-Former-Boss/243864

Campaign for College Opportunity. (2018). Left out: How exclusion in California's colleges and universities hurts our values, our students, and our economy. http://collegecampaign.org/portfolio/left-out-report/

Comeaux, E. (2019). Toward a more critical understanding of the experiences of division I college athletes. Higher Education: Handbook of Theory and Research: Volume 35, 1-53.

Comeaux, E., \& Harrison, C. K. (2011). A conceptual model of academic success for student-athletes. Educational Researcher, 40(5), 235-245.

Commitment to an Athlete's Total Success (CATS). StepUp! Program. University of Arizona. https://stepupprogram.org/contact/ 
Cooky, C. (2012). Success without honor: Cultures of silence and the Penn State scandal. Cultural Studies Critical Methodologies, 12(4), 326-329.

Crenshaw, K. (1991). Mapping the margins: Identity politics, intersectionality, and violence against women. Stanford Law Review, 43(6), 1241-1299.

Donnor, J. K. (2005). Towards an interest-convergence in the education of African-American football student athletes in major college sports. Race Ethnicity and Education, 8(1), 4567.

Doyle, J. (2015). Campus Sex, Campus Security. Semiotext (e).

Duderstadt, J. J. (2003). Intercollegiate athletics and the American university: A university president's perspective. University of Michigan Press.

Duderstadt, J. J. (2004). Governing the twenty-first-century university: A view from the bridge. In W. G. Tierney (Ed.), Competing Conceptions of Academic Governance: Negotiating the Perfect Storm (pp. 137-157). Johns Hopkins University Press.

Fernandez, J. (2019, August 15). Uncovering the mentally abusive culture within UCR's women's basketball program. Highlander News. https://www.highlandernews.org/36007/uncovering-the-mentally-abusive-culture-withinucrs-womens-basketball-program/

Freeh, L. J., Sporkin, F., \& Sullivan, L. L. (2012). Report of the special investigative counsel regarding the actions of Pennsylvania State University related to the child sexual abuse committed by Gerald A. Sandusky. https://drum.lib.umd.edu/bitstream/handle/1903/24449/REPORT_FINAL_071212.pdf?se quence $=1 \&$ is Allowed $=y$

Freeman, H. (2018, January 26) How was Larry Nassar able to abuse so many gymnasts for so long? The Guardian. https://www.theguardian.com/sport/2018/jan/26/larry-nassar-abusegymnasts-scandal-culture

Frey, J. H. (1987). Institutional control of athletics: An analysis of the role played by presidents, faculty, trustees, alumni, and the NCAA. Journal of Sport and Social Issues, 11(1), 4959. 
Gayles, J. G., Comeaux, E., Ofoegbu, E., \& Grummert, S. (2018). Neoliberal capitalism and racism in college athletics: Critical approaches for supporting student-athletes. New Directions for Student Services, 163, 11-21.

Giroux, H. A., \& Giroux, S. S. (2012). Universities gone wild: Big money, big sports, and scandalous abuse at Penn State. Cultural Studies Critical Methodologies, 12(4), 267-273.

Grossman, J. L. (2003). The culture of compliance: The final triumph of form over substance in sexual harassment law. Harvard Women's Law Journal, 26, 3-75.

Gutierrez, A. B., \& McLaren, P. (2012). To be or not to be a snitch or a whistle-blower: Years of silence at Penn State. Cultural Studies Critical Methodologies, 12(4), 309-316.

Harper, S. R., Williams, C. D., \& Blackman, H. W. (2013). Black male student-athletes and racial inequities in NCAA division I college sports. Center for the Study of Race \& Equity in Education, 41.

Harris, J. C., \& Linder, C. (Eds.) (2017). Intersections of identity and sexual violence on campus: Centering minoritized students'experiences. Stylus Publishing, LLC.

Haslerig, S. J., Vue, R., \& Grummert, S. E. (2020). Invincible bodies: American sport media's racialization of Black and White college football players. International Review for the Sociology of Sport, 55(3), 272-290.

Hawkins, B. (2013). The new plantation: Black athletes, college sports, and predominantly White NCAA institutions. Palgrave Macmillan.

Hextrum, K. (2017). Segregated bodies: Gender reproduction within college sport. In A. Milner and J. Braddock (Eds.), Women in sport: Breaking barriers, facing obstacles. Vol. 2, (pp. 169-185). Praeger

Hextrum, K. (2019). Bigger, faster, stronger: How racist and sexist ideologies persist in college sports. Gender and Education, 1-19.

Hextrum, K. (2020). Amateurism revisited: How US college athletic recruitment favors middleclass athletes. Sport, Education and Society, 25(1), 111-123. 
INCITE! Women of Color Against Violence Collective. (2016). Color of violence: The incite! Anthology. Duke University Press.

Jayakumar, U. M., \& Comeaux, E. (2016). The cultural cover-up of college athletics: How organizational culture perpetuates an unrealistic and idealized balancing act. The Journal of Higher Education, 87(4), 488-515.

Jayakumar, U. M., \& Museus, S. D. (2012). Mapping the intersection of campus cultures and equitable outcomes among racially diverse college student populations In Creating campus cultures: Fostering success among racially diverse student populations, 1-27.

Kaplan, G. (2006). Institutions of academic governance and institutional theory: A framework for further research. In J. C. Smart (Ed.), Higher Education: Handbook of Theory and Research, (Vol. XXI., pp. 213-281). Springer

Linder, C. (2018). Sexual violence on campus: Power-conscious approaches to awareness, prevention, and response. Emerald Group Publishing.

Linder, C., \& Harris, J. C. (2017). History, identity, and power-conscious strategies for addressing sexual violence on college campuses. In J. Harris \& C. Linder (Eds.), Intersections of identity and sexual violence on campus: Centering minoritized students' experiences (pp. 235-256). Stylus Publishing, LLC.

Lingenfelter, P., Novak, R., \& Legon, R. (2008). Excellence at scale: What is required of public leadership and governance in higher education? Association of Governing Boards of Universities and Colleges. https://agb.org/sites/default/files/legacy/u3/AGBSHEEO\%20White\%20Paper.pdf

Luther, J. (2016). Unsportsmanlike conduct: College football and the politics of rape. Akashic Books.

Messner, M. A. (1988). Sports and male domination: The female athlete as contested ideological terrain. Sociology of Sport Journal, 5(3), 197-211.

Moynihan, M. M., Banyard, V. L., Arnold, J. S., Eckstein, R. P., \& Stapleton, J. G. (2010). Engaging intercollegiate athletes in preventing and intervening in sexual and intimate partner violence. Journal of American College Health, 59(3), 197-204. 
National Collegiate Athletic Association. (2017, November 28). NCAA Member Institutions. http://www.ncaa.org/about/resources/research/ncaa-member-institutions

National Collegiate Athletic Association. (2018a). Health and Safety. http://www.ncaa.org/health-and-safety

National Collegiate Athletic Association. (2018b). Strategic planning initiative stakeholder analysis summary report. https://catimes.brightspotcdn.com/79/08/38046bd24766ae020ef1197bffef/ncaa2018studyexcerpt.p $\underline{\mathrm{df}}$

New, J. (2016, May 25). Ken Starr to step down. Inside Higher Ed. https://www.insidehighered.com/news/2016/05/25/baylor-university-prepares-firepresident-over-handling-assaults

Nicholson-Crotty, J., \& Meier, K. J. (2003). Politics, structure and public policy: The case of higher education. Educational Policy, 17(1), 80-98.

Nixon, H. L. (2014). The athletic trap: How college sports corrupted the academy. Johns Hopkins University Press.

Ott, M., \& Bates, E. (2015). Leadership in intercollegiate athletics. In E. Comeaux (Ed.), Introduction to intercollegiate athletics (pp. 34-47). John Hopkins University Press.

Padilla, A. (2012). Leadership: Leaders, followers, and environments. Wiley Global Education.

Padilla, A., Hogan, R., \& Kaiser, R. B. (2007). The toxic triangle: Destructive leaders, susceptible followers, and conducive environments. The Leadership Quarterly, 18(3), 176-194.

Parent, S., \& Demers, G. (2011). Sexual abuse in sport: A model to prevent and protect athletes. Child Abuse Review, 20(2), 120-133.

Proffitt, J. M., \& Corrigan, T. F. (2012). Penn State's “success with honor:” How institutional structure and brand logic disincentivized disclosure. Cultural Studies Critical Methodologies, 12(4), 322-325. 
Pusser, B. (2003). Beyond Baldridge: Extending the political model of higher education governance. Educational Policy, 17(1), 121-140.

Pusser, B. (2006). New competition from for-profit education providers. AGB Priorities, 27, 115.

Pusser, B., Slaughter, S., \& Thomas, S. L. (2006). Playing the board game: An empirical analysis of university trustee and corporate board interlocks. The Journal of Higher Education, 77(5), 747-775.

Pusser, B., \& Turner, S. E. (2004). Nonprofit and for-profit governance in higher education. In R. G. Ehrenberg (Ed.), Governing academia. Cornell University Press.

Rall, R. M., Morgan, D. L., \& Commodore, F. (2018). Invisible injustice: Higher education boards and issues of diversity, equity, and inclusivity. In R. Jeffries (Ed.), Diversity, equity, and inclusivity in contemporary higher education (pp. 261-277).

Rall, R. M., Morgan, D. L., \& Commodore, F. (2020). Toward culturally sustaining governance: Best practices of theory, research, and practice. The Journal of Education Human Resources, 38(1), 139-164.

Rall, R. M., \& Orué, V. (2020). I, too, am a lead(her): The power and possibilities of women of color on governing boards of higher education in California. Journal of Higher Education Management, 35(1), 32-39.

Roth, C. (2018, August 30). The NCAA tells Michigan state no rules violated in Larry Nassar scandal. NPR. https://www.npr.org/2018/08/30/643465851/the-ncaa-tells-michigan-stateno-rules-violated-in-larry-nassar-scandal

Sack, A. L., \& Staurowsky, E. J. (1998). College athletes for hire: The evolution and legacy of the NCAA's Amateur Myth. Praeger.

Sartore-Baldwin, M. L., McCullough, B., \& Quatman-Yates, C. (2017). Shared responsibility and issues of injustice and harm within sport. Quest, 69(3), 366-383. 
Seltzer, R. (2018, June 25). Michigan State interim president holds on to job. Inside Higher Ed. https://www.insidehighered.com/quicktakes/2018/06/25/michigan-state-interimpresident-holds-job

Smith, R. A. (1995, May). Intercollegiate athletic reform: An historical view of presidents, governing boards, and faculty. Proceedings and Newsletter-North American Society for Sport History, 18-19.

Smith, R. K. (2000). A brief history of the National Collegiate Athletic Association's role in regulating intercollegiate athletics. Marquette Sports Law Review, 11, 9.

Solomon, D., \& Luther, J. (2015, August 20). Silence at Baylor. Texas Monthly. https://www.texasmonthly.com/article/silence-at-baylor

Tenbrunsel, A. E., \& Messick, D. M. (2004). Ethical fading: The role of self-deception in unethical behavior. Social Justice Research, 17(2), 223-236.

Thoroughgood, C. N., \& Padilla, A. (2013). Destructive leadership and the Penn State scandal: A toxic triangle perspective. Industrial and Organizational Psychology, 6(2), 144-149.

Tierney, W. G. (1988). Organizational culture in higher education: Defining the essentials. The Journal of Higher Education, 59(1), 2-21.

Tierney, W. G., \& Rall, R. M. (2018). Lessons not yet learned: Culture, governance, and the Jerry Sandusky case. American Association of University Administrators, 33(2), 12-21.

Trombino, C., \& Funk, M. (2019). Report of the independent investigation sexual abuse committed by Dr. Richard Strauss at the Ohio State University. Perkins Coi https://compliance.osu.edu/assets/site/pdf/Revised_report.pdf

U.S. Senate Subcommittee on Financial \& Contracting Oversight. (2014). Sexual violence on campus: How too many institutions of higher education are failing to protect students. https://www.mccaskill.senate.gov/SurveyReportwithAppendix.pdf

Westby, D. L., \& Sack, A. (1976). The commercialization and functional rationalization of college football: Its origins. The Journal of Higher Education, 47(6), 625-647. 
Williams, L. M. (2017). Sexual victimization of deaf and hard-of-hearing college students. In J. Harris \& C. Linder (Eds.), Intersections of identity and sexual violence on campus: Centering minoritized students' experiences (pp. 140-154). Stylus Publishing, LLC.

Yiamouyiannis, A., \& Osborne, B. (2012). Addressing gender inequities in collegiate sport: Examining female leadership representation within NCAA sport governance. Sage Open, 2(2), 1-13. 